\title{
OS EXTREMOS TERMO-HIGROMÉTRICOS E OS REGISTROS DE DOENÇAS RESPIRATÓRIAS EM CAMPO GRANDE-MS
}

\section{THE THERMO-HYGROMETRIC EXTREME AND THE RECORDS OF RESPIRATORY DISEASE IN CAMPO GRANDE-MS}

\author{
Arlei Teodoro de Queiroz \\ Instituto Federal de Educação, Ciência e Tecnologia do Triângulo Mineiro \\ arleiteodoro@yahoo.com.br \\ Valdomiro Antônio de Oliveira Lima \\ Instituto Federal de Educação, Ciência e Tecnologia de Mato Grosso do Sul \\ valdomiro.lima@ifms.edu.br \\ Vitória Rodrigues Ferro \\ Instituto Federal de Educação, Ciência e Tecnologia de Mato Grosso do Sul \\ vitoria.ferro@estudante.ifms.edu.br
}

\begin{abstract}
RESUMO
O conhecimento do clima local constitui um importante fator para o estudo do ambiente, bem como a busca de melhor qualidade de vida para a população. Complementando esta ideia, a literatura tem demonstrado que algumas variáveis climáticas, tais como os extremos de temperatura e umidade relativa do ar, podem influenciar na ocorrência de algumas doenças, denominadas doenças sensíveis ao clima (DSC). Neste sentido, o presente estudo tem o objetivo de correlacionar os extremos termo-higrométricos e os registros de doenças respiratórias em Campo Grande-MS. Para atingir o objetivo proposto foram utilizados os dados da Estação Meteorológica de Campo Grande, pertencente a rede de estações do Instituto Nacional de Meteorologia. Foram utilizados, também, os registros de doenças respiratórias disponibilizados pelo Departamento de Informática do SUS. De posse destes dados, os mesmos foram tabulados, classificados e, a partir daí, feita a correlação dos dados utilizando o coeficiente de correlação linear de Pearson. Como resultados, foi possível observar uma correlação, tanto positiva como negativa, dos extremos termohigrométricos e as doenças respiratórias em Campo Grande-MS, sobretudo nos dados compilados de toda a série histórica (2002-2017) e no ano que ocorreu o maior número de óbitos (2016), apresentando índices de correlação mais próximos de 1 ou -1 . Diante dos resultados obtidos, a presente pesquisa serve de base para as diversas áreas do conhecimento que necessitam destas informações para aprimoramento científico, bem como para nortear políticas públicas de saúde que busquem a melhoria do bem-estar social e ambiental da população.
\end{abstract}

Palavras-chave: Extremos termo-higrométricos. Doenças respiratórias. Campo Grande.

\begin{abstract}
The knowledge of the local climate is an important factor for the study of the environment, as well as the search for a better quality of life for the population. Complementing this idea, the literature has shown that some climatic variables, such as extremes of temperature and relative humidity, can influence the occurrence of some diseases, called climate-sensitive diseases (DSC). In this sense, the present study aims to correlate the thermo-hygrometric extremes and the records of respiratory diseases in Campo Grande-MS. To achieve the proposed objective, data from the Meteorological Station of Campo Grande, belonging to the network of stations of the National Institute of Meteorology, were used. Were also used, the respiratory disease records made available by the Informatics Department of SUS. With these data, they were tabulated, classified and, from there, the data was correlated using Pearson's linear correlation coefficient. As a result, it was possible to observe a correlation, both positive and negative, of the thermo-hygrometric extremes and respiratory diseases in Campo Grande-MS, especially in the data compiled from the entire historical series (2002-
\end{abstract}

Recebido em: 05/11/2020

Aceito para publicação em: 19/05/2021.

DOI: http://dx.doi.org/10.14393/Hygeia17058046 $\quad$ Hygeia $\quad$ v.17 $\quad$ p.146-160, 2021 página 146


2017) and in the year that occurred the largest number of deaths (2016), with correlation indexes closer to 1 or -1 . In view of the results obtained, this research serves as a basis for the various areas of knowledge that need this information for scientific improvement, as well as to guide public health policies that seek to improve the social and environmental wellbeing of the population.

Keywords: Thermo-hygrometric extremes. Respiratory diseases. Campo Grande.

\section{INTRODUÇÃO}

O conhecimento da Climatologia de uma região constitui um importante fator para o estudo do ambiente, pois sua dinâmica interfere nos processos hidrológicos, de formação do relevo e dos solos, crescimento e desenvolvimento da vegetação, entre outras ações que compõem a paisagem. Além disso, as condições climáticas podem influenciar na qualidade de vida da população, sendo um dos fatores ambientais que interagem e contribuem para o registro e agravamento de algumas enfermidades, dentre as quais destacam-se neste estudo as doenças respiratórias.

Ainda relacionando o clima e a qualidade de vida, na região do Brasil Central, verifica-se que os principais problemas referentes ao clima dizem respeito a eventos e/ou episódios extremos, sobretudo quanto a períodos de escassez pluviométrica ou precipitações concentradas, causando muitos prejuízos, desde financeiro até perda de vidas humanas. Sendo que estes registros podem ser considerados como eventos meteorológicos extremos, inesperados e incertos, que apresentam índices mais elevados e/ou baixos em um período determinado.

Além dos extremos pluviométricos, vale destacar outros dois elementos climáticos, a temperatura do ar e a umidade relativa do $\mathrm{ar}^{2}$, cuja excepcionalidade corrobora para o desconforto humano (Figura 1), fato que pode contribuir para o agravamento de algumas doenças.

Figura 1 - Diagrama do conforto humano com base na temperatura e umidade relativa do ar

\section{DIAGRAMA DO CONFORTO HUMANO}

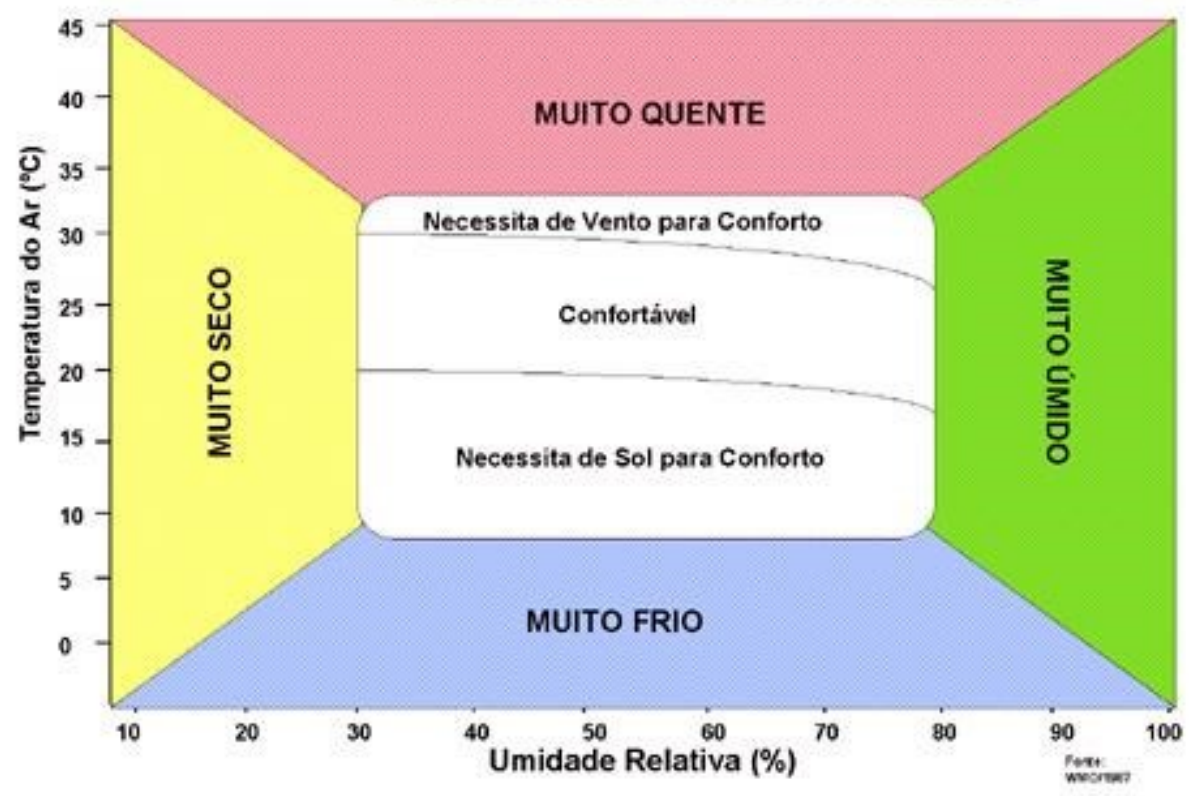

Fonte: INMET, 2020

\footnotetext{
2 De acordo com Mendonça e Danni-Oliveira a umidade relativa "expressa uma relação de proporção relativa entre o vapor existente no ar e o seu ponto de saturação. Em outros termos, ela mostra, em porcentagem, o quanto de vapor está presente no ar em relação à quantidade máxima possível de vapor que poderia haver, sob a mesma temperatura em que se encontra." (MENDONÇA; DANNI-OLIVEIRA, 2007, p. 62)

\begin{tabular}{|c|}
\hline l. httn./dy doi \\
\hline
\end{tabular}
}


Seguindo essa ideia, esse trabalho tem como objeto de estudo os extremos termo-higrométricos ${ }^{3}$ e os registros de doenças respiratórias em Campo Grande-MS, buscando verificar se há correlação entre os dois objetos de estudo.

\section{FUNDAMENTAÇÃO TEÓRICA}

No que diz respeito as influências dos extremos de temperatura do ar e da umidade relativa do ar, sobre os seres humanos, alguns autores destacam a dificuldade de adaptação dos mesmos, sobretudo quando ocorrem oscilações meteorológicas em curto intervalo de tempo. Neste sentido, Mendes (2001, p. 3) afirma que:

Os fenômenos naturais, principalmente os relacionados com a atmosfera, quando se apresentam como eventos extremos, como calor ou frio em excesso, ou ainda estiagens ou precipitações fora dos padrões normais, levam sociedades despreparadas a enfrentar sérios problemas, muitas vezes catastróficos, que repercutem negativamente no bem-estar das populações, principalmente das que habitam as grandes cidades. (MENDES, 2001, p. 3)

Sobre os eventos naturais extremos, White (1974) apud Monteiro (1991) já relatavam que os de origem atmosférica se encontram entre os mais importantes, tanto pela complexidade como pela diversidade dos fenômenos. Dessa maneira, os eventos naturais:

[...] focalizam um aspecto do complexo processo pelo qual o homem interage com os sistemas físico e biológico. Cada parâmetro da biosfera, sujeito a flutuação sazonal, anual ou secular consiste num "hazard" para o homem na medida em que o seu ajustamento à freqüência, magnitude ou desenvolvimento temporal dos eventos extremos são baseados em conhecimento imperfeito. Onde existir previsão acurada e prefeita do que poderá ocorrer e quando ocorrerá na intricada malha dos sistemas atmosférico, hidrológico, e biológico, não existirá "hazard". (...) De modo geral, os eventos extremos apenas podem ser antevistos como probabilidades cujo tempo de ocorrência é desconhecido. (WHITE, 1974, p.3 apud MONTEIRO, 1991, p.8)

Monteiro (1991) ainda salienta que "É imprescindível considerar que a existência de natural hazards ${ }^{4}$ é uma função do "ajustamento humano" a eles, posto que sempre envolvem iniciativa e decisão humana." (MONTEIRO, 1991, p.8). Tendo em vista as informações supracitadas, pode-se afirmar que os eventos naturais relacionados à atmosfera são complexos e diversos, no entanto, cabe ao ser humano, compreender estes eventos, no intuito de planejar e ordenar o território, melhorando, assim, sua capacidade de adaptação a tais intempéries.

A partir do que foi relatado sobre os eventos naturais, vale destacar a descrição feita por Monteiro (2013) no que diz respeito ao risco natural reforçando a ideia de redução da vulnerabilidade, ou seja, melhoria na adaptação ao meio.

[...] a magnitude de um risco natural $(\mathrm{Rn})$ é o produto do tipo de episódio $(E)$ pela vulnerabilidade $(V)$ da populaçãoalvo, parece óbvio que o papel da ciência e da técnica para evitar que um risco climático se transforme numa catástrofe ou numa crise dependa, neste caso, muito mais da competência para diminuir "V" do que da nossa capacidade para controlar "E". (MONTEIRO, 2013, p. 146)

Sabendo da importância de reduzir a susceptibilidade para a qual as pessoas estejam vulneráveis, Monteiro (2013) define que:

Se a vulnerabilidade é a capacidade de antecipar, lutar, resistir e recuperar dos impactos negativos de um episódio gerador de perdas e danos, então o que importa é garantir que a organização social, económica e política compreenda o sistema climático e considere-o nas suas decisões [...] (MONTEIRO, 2013, p. 146)

\footnotetext{
${ }^{3}$ Ao integrar o clima ao planejamento urbano Mendonça (2003) aborda três campos para estudo, sendo que no presente trabalho analisaremos o "Campo Termo-higrométrico, no qual são enfatizados os estudos de ilhas de calor e de frescor urbanas, do conforto/desconforto térmico, de inversões térmicas etc;"(MENDONÇA, 2003, p. 178)

${ }^{4}$ Ao buscar uma tradução para o termo hazards, Monteiro (1991) aponta para seguirmos o entendimento da tradução francesa que compreende o termo como "risco", sendo que "Isto assentaria bem na consideração das componentes antropogênicas, já que o mau uso da natureza aumenta a probabilidade de "riscos", já de si produzidos por ela." (MONTEIRO, 1991, p.9) 
Ao tratar das variáveis termo-higrométrico, Monteiro e Carvalho (2013, p. 107) destacam que "... os seres humanos são das espécies que têm limiares de resistência e adaptabilidade mais estreitos ao contexto termo-higrométrico indoor e outdoor ...".

No que tange a temperatura do ar, Monteiro (2013) ressalta três índices de stress térmico que podem facilitar a compreensão de tal evento extremo:

Os índices racionais baseiam-se em cálculos relacionados com a equação do balanço térmico.

Os índices empíricos apoiam-se na resposta fisiológica humana.

Os índices diretos recorrem à medição, quase sempre de temperatura, em simulações de resposta do corpo humano a ambientes demasiado quentes ou frios. (MONTEIRO, 2013, p. 155-156)

Tendo em vista o referencial supracitado, a climatologia geográfica brasileira tem buscado correlacionar as condições climáticas como um dos elementos que interagem e contribuem para as incidências de algumas enfermidades. Essa linha de estudo foi denominada de climatologia médica, que Murara (2012) descreve como:

Considerando o clima não como fator determinante no desencadeamento das doenças, mas como um elemento que contribui para gênese, desenvolvimento e eclosão, o estudo na Climatologia Médica busca identificar e analisar efeitos favoráveis e desfavoráveis relacionando os elementos climáticos e os diferentes tipos de tempo atmosférico à saúde humana. (MURARA, 2012, p. 1)

Neste sentido, Sousa et al. (2018) faz uma revisão da literatura referente a doenças sensíveis ao clima (DSC), abordando 1162 publicações, das quais 106 foram classificadas como artigos relacionados a DSC. Dos 106 artigos analisados, foram identificadas 37 unidades geográficas abordando estudos em 7 países.

Ainda sobre o trabalho de Sousa et al. (2018), dos 106 artigos analisados, 8 abordaram doenças respiratórias correlacionando com as seguintes variáveis climáticas:

Altura do nível do mar, calor extremo, cobertura de nuvem, direção do vento, horas de sol, insolação, nebulosidade, ondas de calor, ondas de frio, oscilação térmica, pressão ao nível do mar, pressão atmosférica, pressão de vapor, radiação solar, sazonalidade, temperatura, temperaturas extremas, umidade e velocidade do vento (SOUSA et al, 2018, p. 3)

Além disso, Sousa et al. (2018) identificaram as doenças associadas ao clima, dentre as quais as respiratórias se destacaram. Ao utilizar o método de clusterização verificou-se que:

Os resultados referentes à clusterização permitiram analisar a diversidade de variáveis climáticas que têm sido abordadas em relação às principais categorias de DSC estudadas. As doenças respiratórias e cardiovasculares e a dengue apresentaram altos coeficientes de clusterização, indicando que estiveram associadas a um maior número de variáveis climáticas. (SOUSA et al, 2018, p. 5)

Ainda sobre as doenças respiratórias, Sette e Ribeiro destacam o período em que há agravos e os atributos climáticos que mais influenciam na ocorrência de tais enfermidades:

Miranda et al (1995) indicam o aparente aumento da ocorrência dos agravos e de doenças respiratórias agudas e crônicas durante os meses de inverno em São Paulo. Entretanto, ressaltam que, apesar das temperaturas terem um papel importante, não eram determinantes, havendo uma interação de fatores (...)

Em relação aos tipos de tempo em São Paulo, os atributos climáticos que mais influenciam as doenças respiratórias são: a queda da temperatura e da umidade do ar no inverno, a maior amplitude térmica diária, pouca insolação, oscilações bruscas de temperatura, quando da aproximação e passagem de frentes frias e redução da dispersão dos poluentes. (SETTE; RIBEIRO, 2011, p. 44-45)

A partir do que foi relatado, a análise dos extremos termo-higrométricos registrados em Campo Grande-MS e a correlação dos mesmos com o registro de doenças respiratórias torna-se essencial para a busca de ações que atenuem o desconforto térmico gerado por tal intempérie. 


\title{
Notícias e reportagens sobre extremos termo-higrométricos
}

Para melhor compreensão de como a sociedade tem acesso às informações sobre a temática em estudo, utilizou-se, também, de reportagens e sites de divulgação de alertas de extremos termohigrométricos, os quais são descritos a seguir:

\section{"Esqueceram-se dos 70.000 mortos da onda de calor de 2003"}

Em uma entrevista ao Jornal El País, a médica e diretora do Departamento de Saúde Pública, Meio ambiente e Determinantes Sociais da Saúde da Organização Mundial da Saúde (OMS), Maria Neira, falou a respeito do caso onde uma onda de calor em 2003 matou cerca de 70.000 pessoas, " Parece que nós, europeus, esquecemos dos 70.000 mortos de 2003". Na entrevista, Maria ainda fala sobre o impacto que ondas de calor igual a essas pode provocar principalmente em crianças e idosos e nas doenças respiratórias e cardiovasculares.

\section{Inmet alerta para umidade abaixo de $12 \%$ na Capital e onda de calor em MS}

Com a frequente queda da umidade do ar e o aumento da temperatura em Mato Grosso do Sul, o jornal Campo Grande News emitiu um alerta quanto ao iminente risco de se agravarem as doenças respiratórias e cardiovasculares na região, o alerta ainda pedia precaução da população ao realizar atividades físicas e exposição ao sol em dias de calor mais intenso.

\section{METODOLOGIA}

Para realização do presente projeto, primeiramente, foi realizada a revisão da literatura referente ao tema.

Num segundo momento foram utilizados os dados climáticos da Estação Meteorológica Automática de Campo Grande do INMET no período de 2002 a 2017. De posse dos dados, iniciou-se o processo de tabulação e, posteriormente, de classificação dos dados, no intuito de elencar os extremos termohigrométricos de Campo Grande-MS, utilizando para isso editor de planilhas.

Concomitante à aquisição e tratamento dos dados meteorológicos, foram coletados no site do DATASUS os registros de doenças respiratórias no período de 2002 a 2017 (mesmo período em que foram obtidos os dados climáticos). De posse desses dados, foram realizadas as tabulações e classificações, além da construção de alguns gráficos.

A partir das tabelas de extremos termo-higrométricos e registros de doenças respiratórias, foi possível fazer a correlação por meio do coeficiente de correlação linear de Pearson, calculado através da equação descrita por Naghettini e Pinto (2007, p. 358) e apresentada a seguir:

$$
r=\frac{s_{X, Y}}{s_{X} s_{Y}}
$$

Onde: “... r é coeficiente de correlação linear $(-1 \leq r \geq 1)$, SXY é covariância entre as variáveis, $S_{X}$ e sY são os desvios-padrão das amostras..." (NAGHETTINI; PINTO, 2007, p. 358)

Ainda sobre o coeficiente de correlação linear de Pearson, pode-se afirmar que:

\begin{abstract}
... é adimensional e varia entre -1 e +1 , o que não ocorre com a covariância. Assim, as unidades adotadas pelas variáveis não afetam o valor do coeficiente de correlação. Caso os dados se alinhem perfeitamente ao longo de uma reta com declividade positiva teremos a correlação linear positiva perfeita com o coeficiente de Pearson igual a 1. A correlação linear negativa perfeita ocorre quando os dados se alinham perfeitamente ao longo de uma reta com declividade negativa e o coeficiente de correlação de Pearson é igual a -1. O significado de valores intermediários é facilmente percebido. (NAGHETTINI; PINTO, 2007, p. 358)
\end{abstract}

\section{RESULTADOS E DISCUSSÕES}

Tendo como base os dados de extremos termo-higrométricos e de óbitos por doenças do aparelho respiratório, foi possível chegar a alguns resultados que descreveremos a seguir. Para a melhor análise dos dados foram construídos tabelas e gráficos. 
Tabela 1 - Óbitos por doenças do aparelho respiratório em Campo Grande-MS (2002-2017)

\begin{tabular}{|c|c|c|c|c|c|c|c|c|c|c|c|c|c|}
\hline Ano do Óbito & Jan & Fev & Mar & Abr & Mai & Jun & Jul & Ago & Set & Out & Nov & Dez & Total \\
\hline 2002 & 48 & 24 & 36 & 39 & 34 & 30 & 39 & 47 & 45 & 38 & 28 & 41 & 449 \\
\hline 2003 & 29 & 38 & 46 & 36 & 29 & 39 & 43 & 48 & 52 & 39 & 43 & 39 & 481 \\
\hline 2004 & 27 & 36 & 40 & 34 & 46 & 31 & 41 & 36 & 61 & 51 & 35 & 25 & 463 \\
\hline 2005 & 35 & 30 & 40 & 43 & 54 & 42 & 61 & 39 & 41 & 39 & 37 & 48 & 509 \\
\hline 2006 & 42 & 24 & 30 & 38 & 45 & 42 & 48 & 42 & 54 & 40 & 37 & 35 & 477 \\
\hline 2007 & 40 & 49 & 53 & 38 & 43 & 52 & 70 & 53 & 56 & 42 & 47 & 25 & 568 \\
\hline 2008 & 41 & 31 & 31 & 39 & 42 & 46 & 50 & 40 & 41 & 42 & 45 & 44 & 492 \\
\hline 2009 & 43 & 30 & 50 & 53 & 45 & 58 & 63 & 75 & 60 & 49 & 51 & 42 & 619 \\
\hline 2010 & 67 & 35 & 49 & 72 & 48 & 68 & 56 & 77 & 74 & 51 & 49 & 51 & 697 \\
\hline 2011 & 57 & 45 & 71 & 65 & 59 & 47 & 73 & 58 & 47 & 45 & 51 & 46 & 664 \\
\hline 2012 & 43 & 46 & 55 & 51 & 58 & 60 & 86 & 60 & 68 & 65 & 42 & 52 & 686 \\
\hline 2013 & 56 & 35 & 44 & 75 & 59 & 57 & 79 & 74 & 76 & 51 & 50 & 62 & 718 \\
\hline 2014 & 63 & 53 & 44 & 41 & 61 & 90 & 80 & 79 & 61 & 96 & 52 & 53 & 773 \\
\hline 2015 & 48 & 57 & 67 & 69 & 58 & 81 & 83 & 86 & 79 & 78 & 70 & 98 & 874 \\
\hline 2016 & 59 & 61 & 90 & 80 & 110 & 127 & 104 & 89 & 84 & 85 & 77 & 63 & 1029 \\
\hline 2017 & 77 & 61 & 84 & 72 & 98 & 103 & 96 & 80 & 80 & 71 & 63 & 66 & 951 \\
\hline Total & 775 & 655 & 830 & 845 & 889 & 973 & 1072 & 983 & 979 & 882 & 777 & 790 & 10450 \\
\hline$\%$ & 7,4 & 6,3 & 7,9 & 8,1 & 8,5 & 9,3 & 10,3 & 9,4 & 9,4 & 8,4 & 7,4 & 7,6 & 100 \\
\hline
\end{tabular}

Fonte de dados: DATASUS, 2019

Org.: Queiroz, Lima e Ferro, 2020

Os casos de óbitos por meio de doenças no aparelho respiratório, foram tabulados e calculados em 16 anos (2002-2017) e ao analisar tais dados (Tabela 1) percebemos que os anos com maior registro do número de casos foram de 2009 a 2016, só em 2016, ocorreram 1029 óbitos, sendo o ano com maior número de casos. Os meses que se destacam tendo mais casos em relação aos outros nesses 16 anos é o período de abril a outubro, com índices superiores a 8\% por mês. Em 2002 os índices de óbitos foram consideravelmente menores, quando comparados aos de 2016, sendo 439 casos e fevereiro registrou o índice mais baixo de 2002.

Ainda observando os dados da Tabela 1, pode-se concluir que no intervalo de tempo considerado neste trabalho, mais de 10 mil óbitos provocados por doenças respiratórias. Os meses de janeiro e julho apresentam, respectivamente, os menores registros de óbitos, 775 e 1072 casos no período.

Tabela 2 - Temperatura mínima $\left({ }^{\circ} \mathrm{C}\right)$ mensal em Campo Grande-MS (2002-2017)

\begin{tabular}{|c|c|c|c|c|c|c|c|c|c|c|c|c|c|}
\hline Ano/mês & Jan & Fev & Mar & Abr & Mai & Jun & Jul & Ago & Set & Out & Nov & Dez & $\begin{array}{c}\text { Temp. } \\
\text { mín. }\end{array}$ \\
\hline 2002 & 15,7 & 18,4 & 19,6 & 17,7 & 10,2 & 10,8 & 5,0 & 9,9 & 4,0 & 17,3 & 16,4 & 19,8 & 4,0 \\
\hline 2003 & 19,2 & 19,2 & 15,4 & 10,0 & 7,4 & 14,1 & 8,8 & 6,0 & 6,3 & & 17,6 & 18,4 & 6,0 \\
\hline 2004 & 18,8 & 18,2 & 15,2 & 14,7 & 7,3 & 4,3 & 7,6 & 7,2 & 8,6 & 13,9 & 14,5 & 17,9 & 4,3 \\
\hline 2005 & 19,6 & 17,2 & 16,7 & 11,0 & 11,2 & 13,5 & 6,8 & 4,8 & 8,5 & 16,7 & 18,5 & 19,0 & 4,8 \\
\hline 2006 & 18,8 & 17,7 & 19,0 & 17,4 & 9,5 & 10,5 & 8,9 & 8,1 & 4,7 & 16,4 & 12,7 & 19,3 & 4,7 \\
\hline 2007 & 19,7 & 19,1 & 14,6 & 13,1 & 4,7 & & 5,4 & 8,1 & 10,3 & 18,3 & 15,8 & 19,4 & 4,7 \\
\hline 2008 & 19,3 & 17,9 & 16,9 & 13,1 & 8,0 & 6,9 & 12,8 & 10,4 & 7,9 & 16,2 & 16,3 & 13,8 & 6,9 \\
\hline 2009 & 14,5 & 18,9 & 17,8 & 15,8 & 9,5 & 6,7 & 4,3 & 8,0 & 12,5 & 15,0 & 20,3 & 18,4 & 4,3 \\
\hline 2010 & 19,1 & 20,5 & 17,2 & 12,9 & 6,4 & 8,2 & 5,9 & 6,6 & 12,3 & 14,2 & 14,2 & 15,0 & 5,9 \\
\hline 2011 & 19,9 & & & & 9,4 & 3,7 & 6,9 & 6,1 & 11,8 & 17,0 & 16,1 & 16,3 & 3,7 \\
\hline 2012 & 18,3 & 18,9 & 12,3 & 10,7 & 8,5 & 7,7 & 5,8 & 9,1 & 9,3 & 16,6 & 18,9 & 19,6 & 5,8 \\
\hline 2013 & 18,5 & 18,7 & 13,4 & 13,0 & 10,2 & 12,4 & 4,3 & 3,1 & 6,9 & 15,3 & 14,0 & 18,1 & 3,1 \\
\hline 2014 & 18,6 & 18,9 & 17,4 & 14,1 & 9,6 & 7,7 & 7,7 & 10,9 & 13,7 & 16,0 & 14,8 & 18,7 & 7,7 \\
\hline 2015 & 18,2 & 19,3 & 18,3 & 16,7 & 11,8 & 11,9 & 9,0 & 14,1 & 10,2 & 13,6 & 18,5 & 18,3 & 9,0 \\
\hline 2016 & 17,3 & 20,1 & 16,5 & 7,1 & 9,9 & 4,3 & 5,3 & 6,4 & 10,0 & 11,3 & 15,3 & 17,3 & 4,3 \\
\hline 2017 & 18,0 & 18,9 & 18,8 & 12,1 & 15,7 & 6,1 & 4,3 & 9,2 & 14,5 & 12,9 & 14,3 & 18,3 & 4,3 \\
\hline $\begin{array}{c}\text { Temp. } \\
\text { mín. }\end{array}$ & 14,5 & 17,2 & 12,3 & 7,1 & 4,7 & 3,7 & 4,3 & 3,1 & 4,0 & 11,3 & 12,7 & 13,8 & 3,1 \\
\hline
\end{tabular}

Fonte de dados: INMET, 2019

Org.: Queiroz, Lima e Ferro, 2020

Ao observar a Tabela 2, que apresenta os dados de temperatura mínima mensal no período de 2002 a 2017, nota-se que os meses que registraram temperaturas mais baixas, abaixo de $5^{\circ} \mathrm{C}$, foram de maio a setembro, sendo que nos meses de junho e agosto houve registro de temperatura inferior a $4^{\circ} \mathrm{C}$. Já no intervalo de outubro a março os registros de temperatura mínima foram superiores a $10^{\circ} \mathrm{C}$. 
Gráfico 1 - Temperatura mínima e óbitos por doenças respiratórias em Campo Grande-MS (20022017)

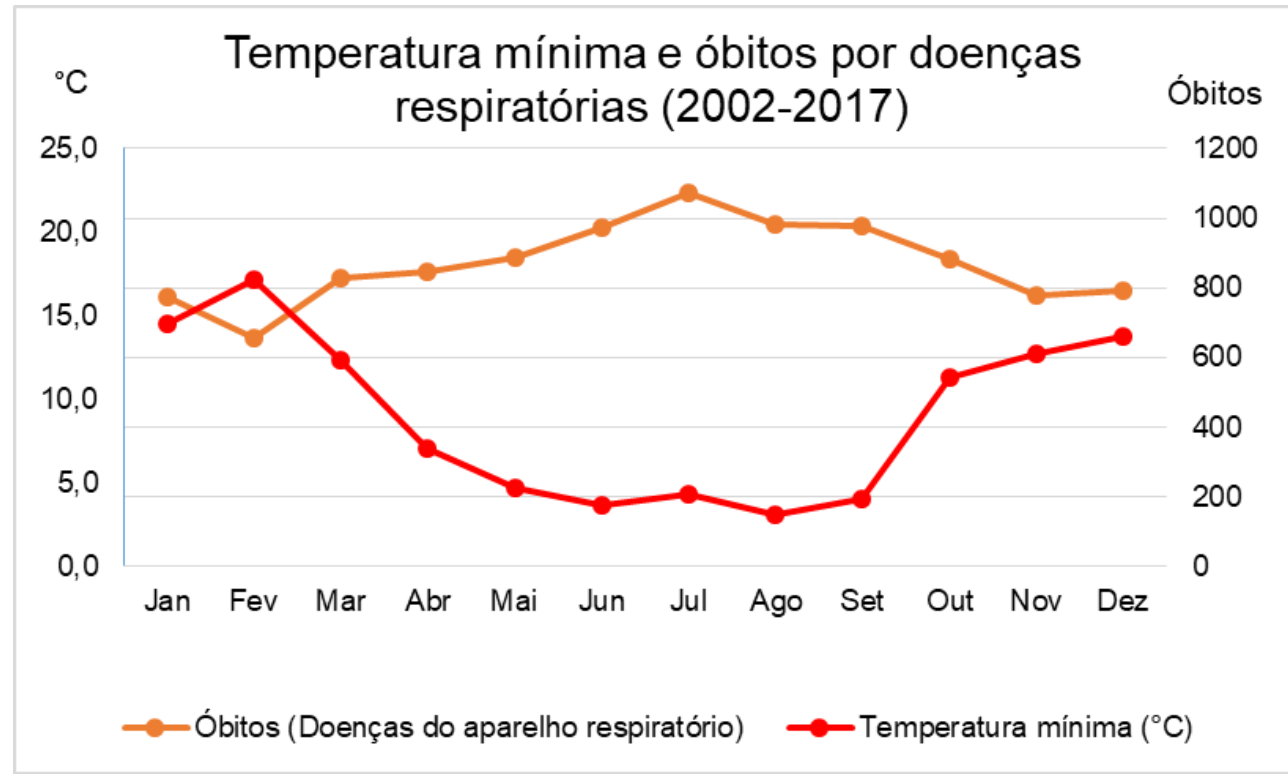

Fonte de dados: INMET; DATASUS, 2019

Org.: Queiroz, Lima e Ferro, 2020

Relacionando os dois indicadores no decorrer do período analisado, percebemos que os meses em que temperatura mínima é mais baixa, o número de óbitos tende a ser consideravelmente maiores (Gráfico 1). A menor temperatura registrada nesses 16 anos foi de $3,1^{\circ} \mathrm{C}$ no mês de agosto de 2013 e o mês em que a temperatura mínima no período foi mais elevada foi fevereiro com $17,2^{\circ} \mathrm{C}$. Coincidentemente o mês mais quente (fevereiro) é o que possui menor número de óbitos, totalizando $6,3 \%$ dos registros em 2002. O mês com maior número de óbitos foi julho, responsável por 10,3\%.

Gráfico 2 - Temperatura mínima e óbitos por doenças respiratórias em Campo Grande-MS (2002)

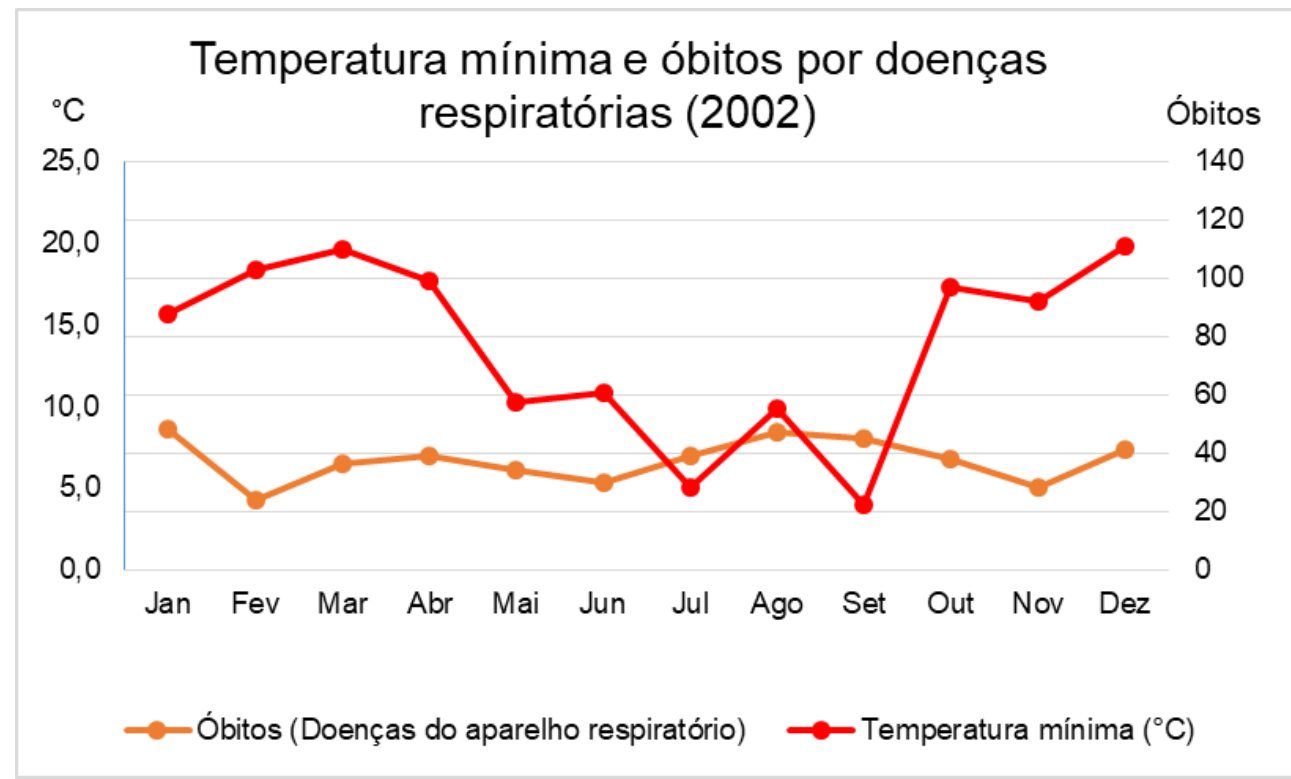

Fonte de dados: INMET; DATASUS, 2019

Org.: Queiroz, Lima e Ferro, 2020 
O ano de 2002 destacou-se como sendo o ano com menor índice de óbitos quando levado em consideração a correlação com a temperatura mínima (Tabelas 1 e 2). Neste ano as oscilações em relação à temperatura mínima foram consideráveis, tendo os registros mais elevados no início (janeiro a abril) e final do ano (outubro a dezembro), superando a temperatura mínima de $15^{\circ} \mathrm{C}$. Neste mesmo período encontramos os dois meses com menor número de óbitos (fevereiro e novembro), com número de óbitos inferior a 30 casos.

Nos meses em que a temperatura mínima tende a ficar mais baixa (maio a setembro), inferior a $10^{\circ} \mathrm{C}$, o número de óbitos aumentou, atingindo mais de 45 casos nos meses de julho e setembro.

Gráfico 3 - Temperatura mínima e óbitos por doenças respiratórias em Campo Grande-MS (2016)

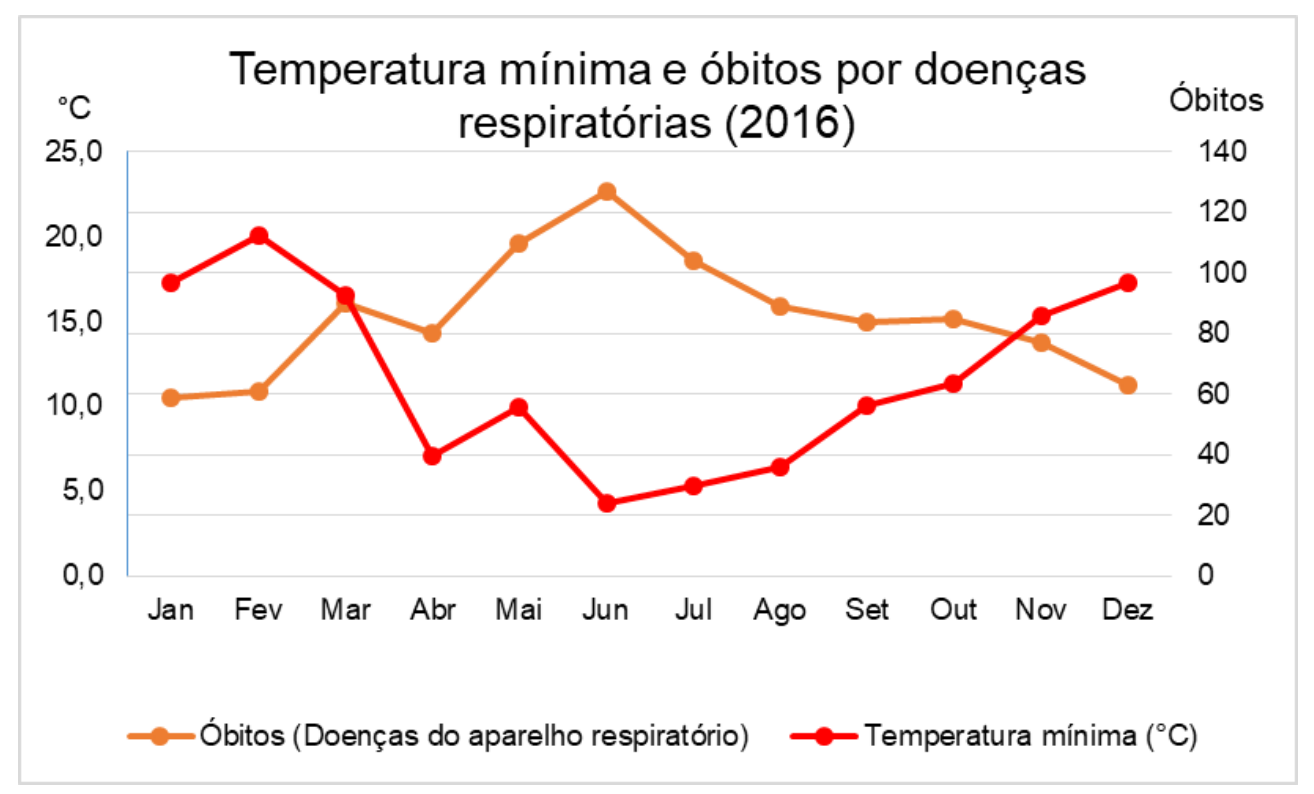

Fonte de dados: INMET; DATASUS, 2019

Org.: Queiroz, Lima e Ferro, 2020

Em 2016, ocorreram mais de 1020 registros de óbitos, com maior número de casos em junho, chegando a 127 casos. Nos meses de junho e julho a temperatura mínima ficou em torno de $5^{\circ} \mathrm{C}$. Os meses que apresentaram os menores registros de óbitos foram janeiro, fevereiro e dezembro (em torno de 60 casos por mês) e a temperatura mínima registrada nestes meses foram as mais altas, superando $17^{\circ} \mathrm{C}$.

Por fim, ao observar os gráficos, pode-se verificar que a temperatura mínima pode influenciar nas doenças no aparelho respiratório, contribuindo para o aumento do número de óbitos.

Analisando as Tabelas 1 e 3 , referentes às temperaturas máximas e aos óbitos por doenças no aparelho respiratório é possível indicar uma tendência de redução do número de óbitos com o aumento da temperatura conforme pode ser observado no Gráfico 4.

De 2002 a 2017 (Tabela 3 e Gráfico 4), os meses com temperaturas mais elevadas, acima de $35^{\circ} \mathrm{C}$, foram registradas no período compreendido entre agosto e abril, sendo que nos meses de janeiro e outubro houve registro de temperatura superior a $40^{\circ} \mathrm{C}$. Já no que tange aos registros de óbitos por doenças do aparelho respiratório, no período de novembro a março os índices foram inferiores a $8 \%$. Em contrapartida, nos meses de junho a setembro os casos foram significativamente mais altos, com julho atingindo um total de $1072(10,3 \%)$ óbitos no período analisado. Vale destacar que dois (junho e julho) dos quatro meses citados com maior número de óbitos, os registros de temperatura máxima foram mais baixas, sendo inferiores a $33,5^{\circ} \mathrm{C}$. 
Tabela 3 - Temperatura máxima $\left({ }^{\circ} \mathrm{C}\right)$ mensal em Campo Grande-MS (2002-2017)

\begin{tabular}{|c|c|c|c|c|c|c|c|c|c|c|c|c|c|}
\hline Ano/mês & Jan & Fev & Mar & Abr & Mai & Jun & Jul & Ago & Set & Out & Nov & Dez & $\begin{array}{l}\text { Temp. } \\
\text { máx. }\end{array}$ \\
\hline 2002 & 33,3 & 34,0 & 34,4 & 34,3 & 32,2 & 31,7 & 33,5 & 35,1 & 35,6 & 36,6 & 34,7 & 35,2 & 36,6 \\
\hline 2003 & 34,4 & 33,1 & 33,1 & 32,4 & 31,4 & 29,9 & 32,0 & 33,7 & 36,4 & & 32,0 & 33,6 & 36,4 \\
\hline 2004 & 35,6 & 34,2 & 35,0 & 20,7 & 31,0 & 30,2 & 30,2 & 35,6 & 38,9 & 35,7 & 34,7 & 34,8 & 38,9 \\
\hline 2005 & 33,5 & 36,0 & 33,5 & 34,9 & 32,1 & 30,7 & 31,6 & 34,1 & 35,0 & 35,3 & 34,4 & 33,7 & 36,0 \\
\hline 2006 & 40,2 & 34,0 & 33,4 & 33,0 & 31,0 & 30,6 & 32,3 & 35,8 & 35,5 & 35,1 & 35,1 & 34,1 & 40,2 \\
\hline 2007 & 33,4 & 33,3 & 35,8 & 35,5 & 33,9 & & 32,9 & 35,2 & 37,5 & 38,2 & 34,6 & 36,0 & 38,2 \\
\hline 2008 & 33,2 & 32,3 & 32,8 & 32,6 & 31,0 & 29,3 & 32,9 & 34,7 & 38,2 & 38,3 & 35,6 & 36,9 & 38,3 \\
\hline 2009 & 32,4 & 33,9 & 35,9 & 32,8 & 32,7 & 30,9 & 30,8 & 33,4 & 35,5 & 34,6 & 35,2 & 33,5 & 35,9 \\
\hline 2010 & 33,5 & 35,4 & 33,8 & 33,4 & 31,7 & 32,0 & 32,5 & 37,5 & 37,4 & 35,7 & 34,9 & 34,8 & 37,5 \\
\hline 2011 & 33,2 & & & & 28,4 & 31,7 & 33,4 & 36,3 & 36,8 & 34,5 & 35,2 & 34,9 & 36,8 \\
\hline 2012 & 33,7 & 34,7 & 39,4 & 33,2 & 30,7 & 30,3 & 32,4 & 33,8 & 39,2 & 37,9 & 34,3 & 34,0 & 39,4 \\
\hline 2013 & 34,6 & 33,7 & 34,0 & 31,8 & 32,4 & 29,4 & 32,2 & 34,7 & 35,6 & 34,6 & 34,9 & 34,7 & 35,6 \\
\hline 2014 & 33,1 & 35,1 & 32,8 & 33,9 & 30,5 & 30,2 & 31,4 & 35,1 & 36,3 & 40,2 & 34,3 & 33,5 & 40,2 \\
\hline 2015 & 34,6 & 35,3 & 33,7 & 32,3 & 32,0 & 30,7 & 32,5 & 37,1 & 37,8 & 37,4 & 35,2 & 33,9 & 37,8 \\
\hline 2016 & 34,1 & 34,9 & 34,8 & 35,3 & 31,7 & 30,4 & 33,0 & 35,5 & 36,1 & 35,6 & 34,5 & 33,7 & 36,1 \\
\hline 2017 & 34,6 & 34,4 & 33,5 & 32,8 & 32,0 & 30,7 & 32,1 & 36,5 & 38,1 & 37,8 & 34,1 & 34,7 & 38,1 \\
\hline $\begin{array}{l}\text { Temp. } \\
\text { máx. }\end{array}$ & 40,2 & 36,0 & 39,4 & 35,5 & 33,9 & 32,0 & 33,5 & 37,5 & 39,2 & 40,2 & 35,6 & 36,9 & 40,2 \\
\hline
\end{tabular}

Fonte de dados: INMET, 2019

Org.: Queiroz, Lima e Ferro, 2020

Gráfico 4 - Temperatura máxima e óbitos por doenças respiratórias em Campo Grande-MS (20022017)



Fonte de dados: INMET; DATASUS, 2019

Org.: Queiroz, Lima e Ferro, 2020

Ao analisar os dados do ano de 2002 (Gráfico 5), quando houve o menor registro de óbitos percebese que a variação da temperatura máxima mensal foi baixa, oscilando entre 30 e $36^{\circ} \mathrm{C}$. Quanto aos óbitos, no mesmo ano, foram menores nos meses de fevereiro, junho e novembro, não ultrapassando os 30 casos por mês. Janeiro, agosto, setembro e dezembro destacam-se por serem os meses do ano com maior número de óbitos, mais de $40 \%$ do total anual. Diante do exposto e observando o Gráfico 5, nota-se uma baixa relação entre as temperaturas máximas e os óbitos por doenças respiratórias no ano em questão. 
Gráfico 5 - Temperatura mínima e óbitos por doenças respiratórias em Campo Grande-MS (2002)

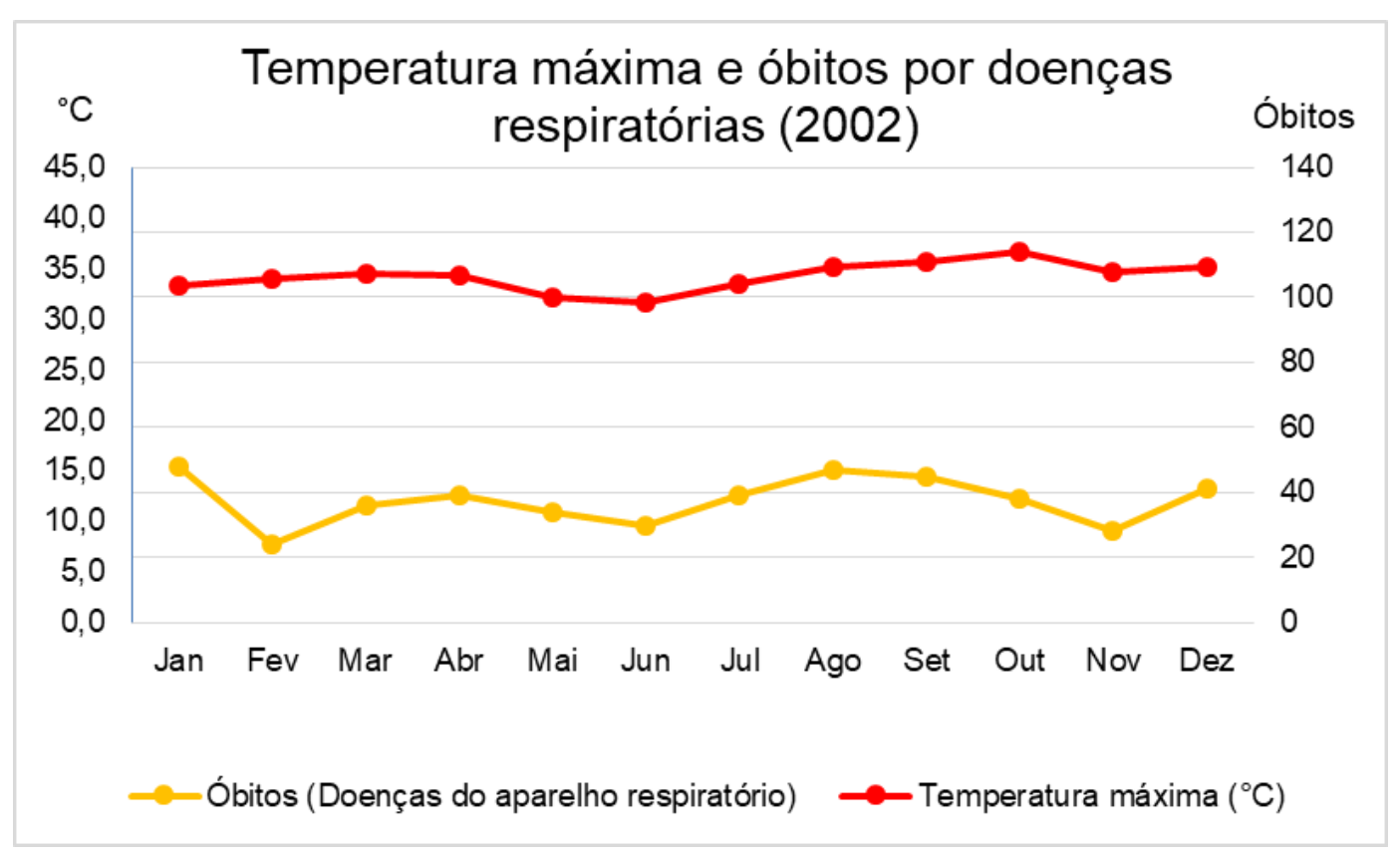

Fonte de dados: INMET; DATASUS, 2019

Org.: Queiroz, Lima e Ferro, 2020

O ano 2016 se destacou como o ano cujo as temperaturas máximas e o número de óbitos oscilaram com uma discrepância significativa, quando comparada ao de 2002. Os dados registrados apontaram que no mês de junho os números de óbitos aumentaram de modo considerável, foram 127 registros de óbitos, tornando-o o mês com maior número de casos dentre esses 16 anos (2002-2017), sendo que a temperatura máxima registrada neste mês foi de $30,4^{\circ} \mathrm{C}$, a menor dentre as máximas, registradas no ano em questão. Os meses com menor número de registros de óbitos foram janeiro, fevereiro e dezembro, em torno de 60 óbitos por mês. Nestes mesmos meses, a temperatura máxima foi por volta de $34^{\circ} \mathrm{C}$.

Gráfico 6 - Temperatura máxima e óbitos por doenças respiratórias em Campo Grande-MS (2016)

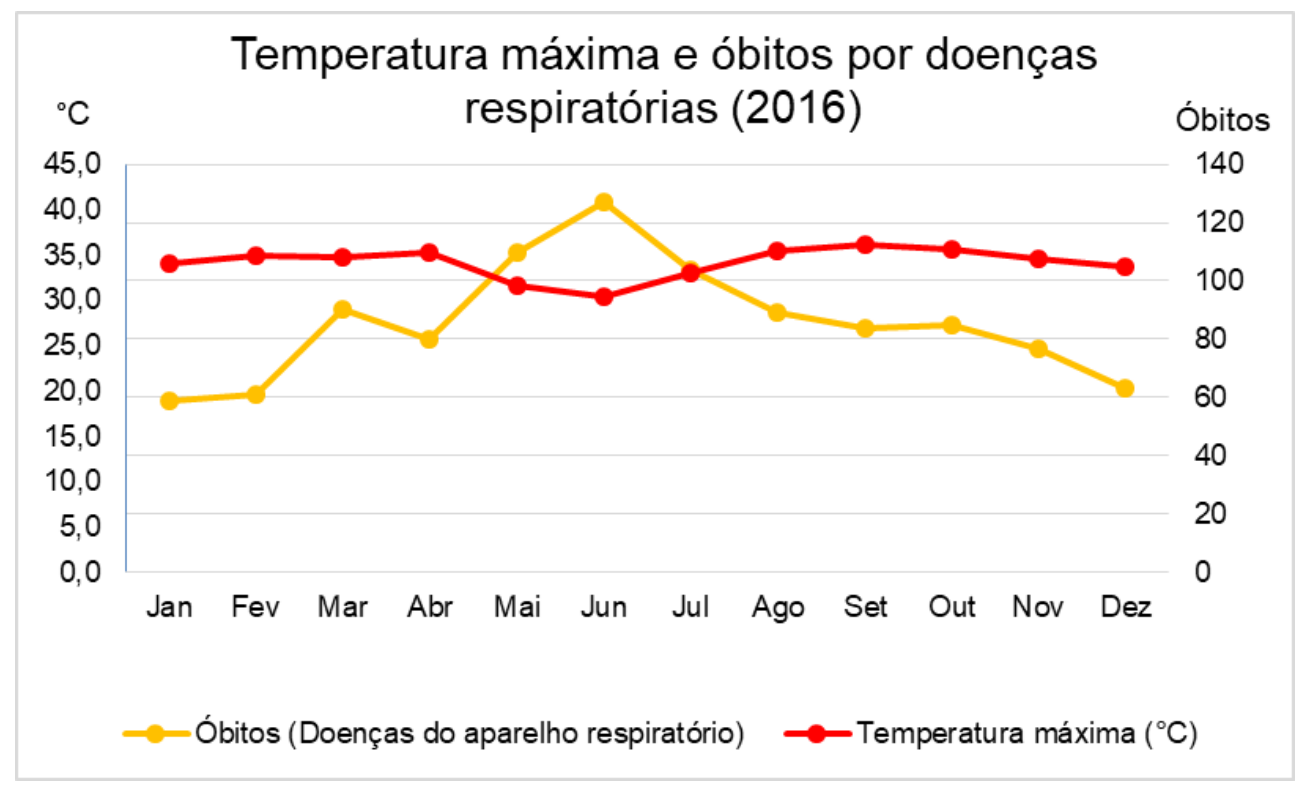

Fonte de dados: INMET; DATASUS, 2019

Org.: Queiroz, Lima e Ferro, 2020 
Ainda sobre os dados do ano 2016, é possível observar que nos meses em que a temperatura máxima foi acima de $33^{\circ} \mathrm{C}$ o número de óbitos foi inferior a 100 caso, já quando a temperatura máxima foi até $33^{\circ} \mathrm{C}$ houve uma elevação no número de óbitos, superando 100 casos por mês.

Tabela 4 - Umidade relativa do ar mínima (\%) mensal em Campo Grande-MS (2002-2017)

\begin{tabular}{|c|c|c|c|c|c|c|c|c|c|c|c|c|c|}
\hline Ano/mês & Jan & Fev & Mar & Abr & Mai & Jun & Jul & Ago & Set & Out & Nov & Dez & $\begin{array}{l}\text { Umid. } \\
\text { mín. }\end{array}$ \\
\hline 2002 & 29,0 & 25,0 & 34,0 & 22,0 & 27,0 & 21,0 & 20,0 & 15,0 & 11,0 & 23,0 & 19,0 & 31,0 & 11,0 \\
\hline 2003 & 36,0 & 35,0 & 36,0 & 23,0 & 21,0 & 23,0 & 17,0 & 10,0 & 15,0 & & 53,0 & 34,0 & 10,0 \\
\hline 2004 & 22,0 & 27,0 & 19,0 & 35,0 & 37,0 & 30,0 & 23,0 & 12,0 & 10,0 & 16,0 & 22,0 & 27,0 & 10,0 \\
\hline 2005 & 36,0 & 23,0 & 22,0 & 26,0 & 25,0 & 23,0 & 23,0 & 13,0 & 21,0 & 31,0 & 29,0 & 29,0 & 13,0 \\
\hline 2006 & 26,0 & 34,0 & 33,0 & 29,0 & 23,0 & 27,0 & 14,0 & 9,0 & 16,0 & 24,0 & 23,0 & 32,0 & 9,0 \\
\hline 2007 & 46,0 & 32,0 & 27,0 & 24,0 & 23,0 & & 18,0 & 14,0 & 9,0 & 15,0 & 25,0 & 18,0 & 9,0 \\
\hline 2008 & 38,0 & 29,0 & 24,0 & 30,0 & 22,0 & 18,0 & 15,0 & 14,0 & 13,0 & 17,0 & 22,0 & 21,0 & 13,0 \\
\hline 2009 & 26,0 & 32,0 & 27,0 & 19,0 & 26,0 & 24,0 & 26,0 & 20,0 & 27,0 & 23,0 & 38,0 & 39,0 & 19,0 \\
\hline 2010 & 41,0 & 36,0 & 26,0 & 28,0 & 30,0 & 23,0 & 18,0 & 11,0 & 11,0 & 15,0 & 18,0 & 40,0 & 11,0 \\
\hline 2011 & 39,0 & & & & 28,0 & 23,0 & 15,0 & 12,0 & 12,0 & 23,0 & 22,0 & 21,0 & 12,0 \\
\hline 2012 & 24,0 & 26,0 & 17,0 & 28,0 & 24,0 & 26,0 & 16,0 & 13,0 & 11,0 & 19,0 & 29,0 & 34,0 & 11,0 \\
\hline 2013 & 31,0 & 37,0 & 19,0 & 23,0 & 19,0 & 29,0 & 14,0 & 12,0 & 13,0 & 19,0 & 30,0 & 32,0 & 12,0 \\
\hline 2014 & 34,0 & 25,0 & 39,0 & 34,0 & 32,0 & 31,0 & 21,0 & 17,0 & 14,0 & 13,0 & 21,0 & 40,0 & 13,0 \\
\hline 2015 & 31,0 & 31,0 & 31,0 & 27,0 & 31,0 & 27,0 & 21,0 & 16,0 & 12,0 & 21,0 & 34,0 & 36,0 & 12,0 \\
\hline 2016 & 25,0 & 36,0 & 29,0 & 27,0 & 28,0 & 25,0 & 29,0 & 32,0 & 38,0 & 47,0 & 35,0 & 35,0 & 25,0 \\
\hline 2017 & 34,0 & 31,0 & 41,0 & 21,0 & 33,0 & 24,0 & 18,0 & 17,0 & 14,0 & 18,0 & 20,0 & 29,0 & 14,0 \\
\hline $\begin{array}{l}\text { Umid. } \\
\text { mín. }\end{array}$ & 22,0 & 23,0 & 17,0 & 19,0 & 19,0 & 18,0 & 14,0 & 9,0 & 9,0 & 13,0 & 18,0 & 18,0 & 9,0 \\
\hline
\end{tabular}

Fonte de dados: INMET, 2019

Org.: Queiroz, Lima e Ferro, 2020

Quando observados os dados de umidade relativa do ar mínima e o número de óbitos por de doenças no aparelho respiratório (Tabelas 1 e 4), de modo geral constata-se que entre 2002 e 2017 o mês de julho apresentou 1072 casos de óbitos e umidade relativa mínima de 14\%, sendo esse o mês com mais óbitos dentre estes 16 anos. No final (novembro e dezembro) e início do ano (janeiro e fevereiro) o número de óbitos tem uma redução perceptível, tendo um total por mês inferior a 800 casos de óbitos nos 16 anos objetos deste estudo. A umidade relativa mínima nesse período supera os $18 \%$. Mesmo a umidade relativa do mínima sendo baixa (conforme pode ser observado na Figura 1), ao comparar com os meses de julho a outubro percebe-se que há uma ligeira queda da umidade nos meses de inverno e início da primavera no hemisfério Sul (Gráfico 7).

Gráfico 7 - Umidade relativa do ar mínima e óbitos por doenças respiratórias em Campo Grande-MS (2002-2017)

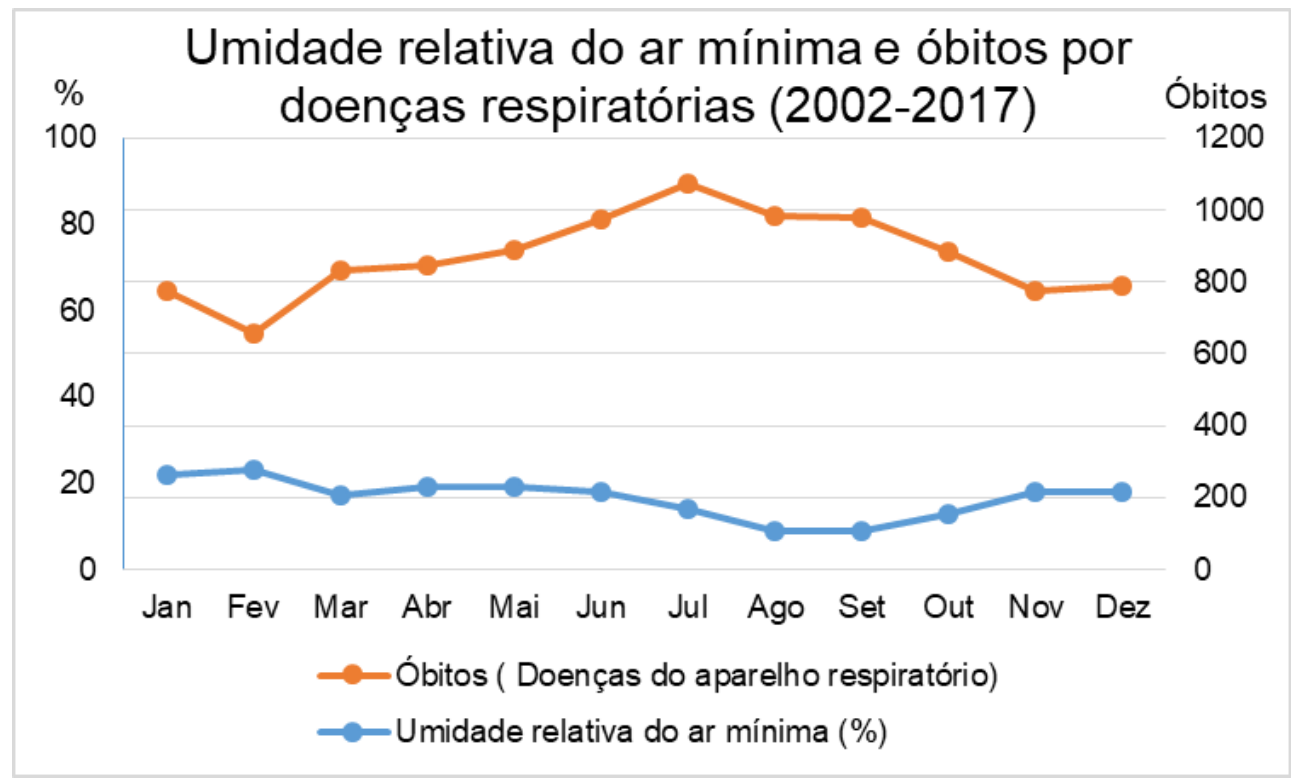

Fonte de dados: INMET; DATASUS, 2019 


\section{Org.: Queiroz, Lima e Ferro, 2020}

Ao observar o Gráfico 8 que apresenta os dados umidade relativa mínima do ar e os dados de óbitos por doenças no aparelho respiratório no ano de 2002 nota-se uma relação inversa no período de julho a setembro, quando a umidade relativa mínima diminui e o registro de óbitos aumenta. Os meses com menor e maior umidade relativa mínima, respectivamente, foram setembro, com $11 \%$ e março com $34 \%$. Nestes meses os números de óbitos foram de 45 e 36, respectivamente.

Gráfico 8: Umidade relativa do ar mínima e óbitos por doenças respiratórias em Campo Grande-MS (2002)

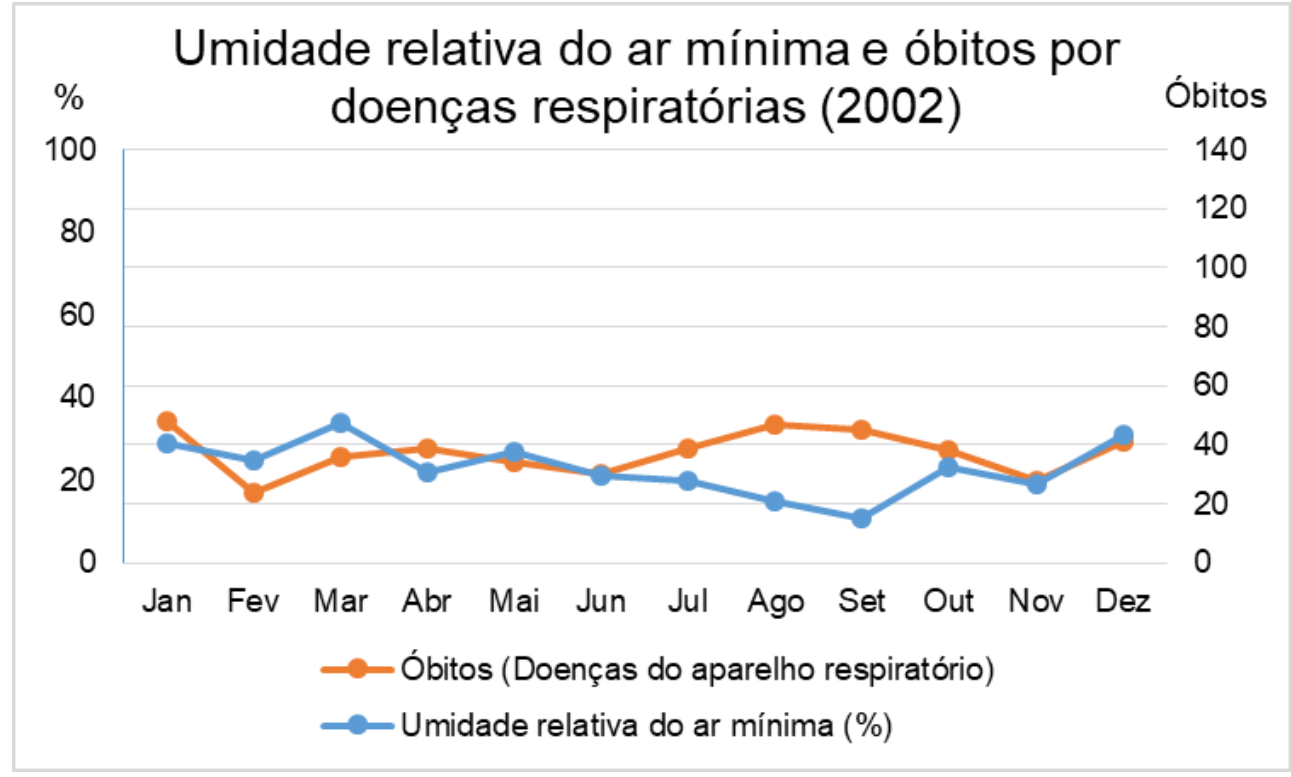

Fonte de dados: INMET; DATASUS, 2019

Org.: Queiroz, Lima e Ferro, 2020

Ao analisar o Gráfico 9, referente aos dados de umidade relativa do ar mínima e os óbitos por doenças respiratórias no ano de 2016, nota-nos meses de março a julho a umidade relativa mínima do ar atingiu índices inferiores a 30\%, considerado estado de atenção pela Organização Mundial de Saúde (OMS). Já no que se refere aos óbitos, neste mesmo período, destaca-se os meses de maio a julho com o registro de mais de 100 óbitos por mês.

Fazendo-se uma análise geral dos dados de umidade mínima e comparando os dois anos em destaque (2002 e 2016), pode-se perceber que, assim como, os resultados que levaram em conta as temperaturas, mínimas e máximas e o número de óbitos por doenças no aparelho respiratório, a relação entre óbitos e a umidade, apontam para uma correlação, sendo que no caso da umidade, quanto maior o índice, menor é o número de registro de óbitos e quanto menor a umidade maior o número de casos. Assim, conclui-se que esses três fatores, temperatura mínima, temperatura máxima e umidade mínima relativa do ar, podem influenciar no agravamento no número de óbitos decorrentes de doenças no sistema respiratório.

Para melhor compreensão da correlação entre os extremos termo-higrométricos e os óbitos por doenças respiratórias, a Tabela 5 apresenta o coeficiente de correlação linear de Pearson para os elementos analisados neste trabalho. De posse deste coeficiente entendemos qual a correlação entre os dados de temperaturas/óbitos e umidade/óbitos. 
Gráfico 9 - Umidade relativa do ar mínima e óbitos por doenças respiratórias em Campo Grande-MS (2016)

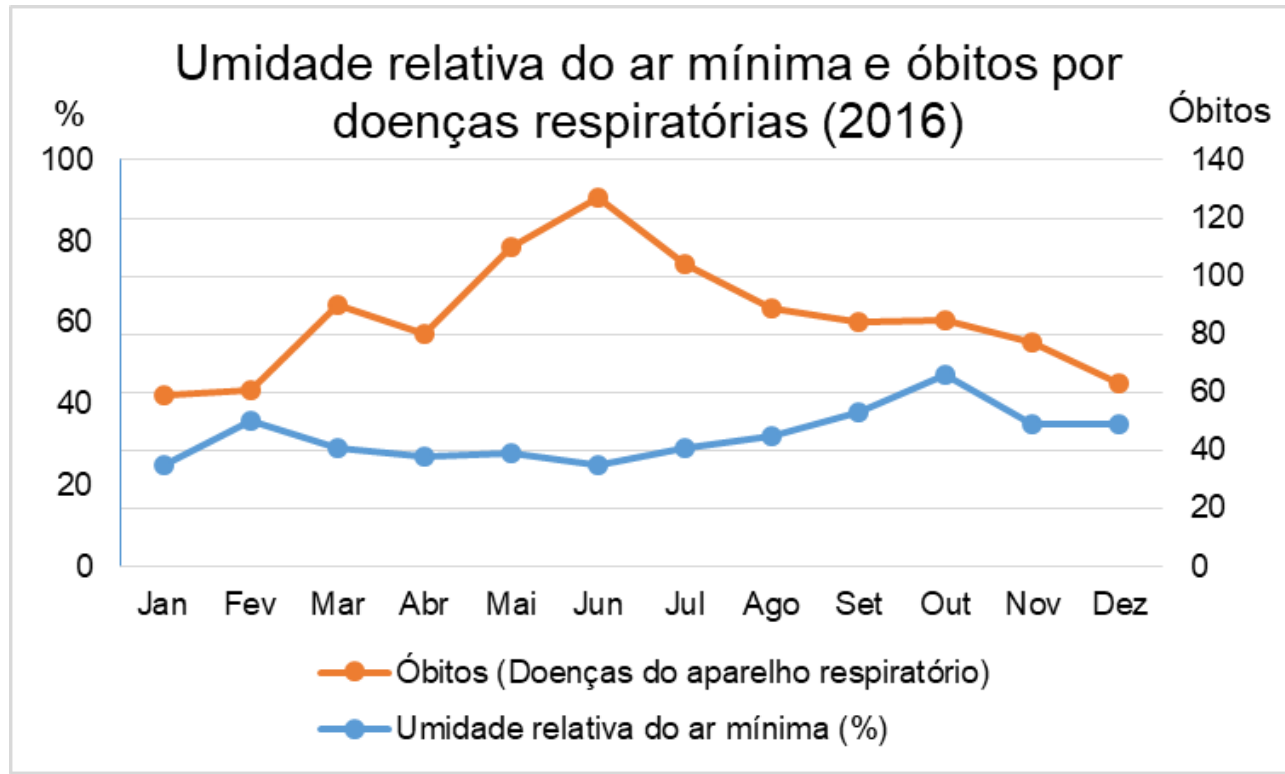

Fonte de dados: INMET; DATASUS, 2019

Org.: Queiroz, Lima e Ferro, 2020

Tabela 5 - Coeficiente de correlação linear de Pearson para os dados de extremos termohigrométricos e óbitos por doenças respiratórias em Campo Grande-MS (2002-2017)

Coeficiente de correlação linear de Pearson

\begin{tabular}{cccc}
\hline & $\begin{array}{c}\text { Temperatura } \\
\text { mínima/óbitos }\end{array}$ & $\begin{array}{c}\text { Temperatura } \\
\text { máxima/óbitos }\end{array}$ & $\begin{array}{c}\text { Umidade } \\
\text { relativa do ar } \\
\text { mínima/óbitos }\end{array}$ \\
\hline Total & $-0,903$ & $-0,272$ & $-0,741$ \\
2002 & $-0,297$ & 0,320 & $-0,157$ \\
2016 & $-0,781$ & $-0,651$ & $-0,314$ \\
\hline
\end{tabular}

Fonte de dados: INMET; DATASUS, 2019

Org.: Queiroz, Lima e Ferro, 2020

Ao analisar o ano de 2002, percebemos que os registros de temperatura e umidade mínima tiveram seus coeficientes negativos e mais próximos de 0 , sendo assim podemos afirmar que as duas variáveis, temperatura e umidade mínima e óbito, não estão totalmente correlacionadas. Já a correlação entre óbito e temperatura máxima, ainda em 2002, manteve-se mais próxima de 0 , positivamente, ou seja, essa relação, por mais que seja positiva, ainda indica que os óbitos não são totalmente relacionados à temperatura máxima.

Em 2016 os coeficientes apresentados demonstraram oscilações relevantes quando comparado a 2002, sendo que a correlação temperatura máxima e mínima/óbitos manteve-se mais próxima de -1 , ou seja, os óbitos, segundo os dados indicados pelo coeficiente de Pearson, têm grande correlação, isso indica que sempre que um indicador aumentou o outro diminuiu. Aumentando, então, a temperatura, tanto máxima como mínima, os óbitos caíram. Já o coeficiente para umidade mínima/óbitos, manteve-se mais próximo de 0 , assim percebe-se que não há uma total correlação entre as duas variáveis.

Analisando por fim as variáveis óbitos por doenças respiratórias e extremos termo-higrométricos ao longo do período analisado (2002-2017), percebe-se que os extremos de temperatura e umidade 
mínimas, apresentaram o coeficiente mais próximo de -1, logo percebe-se que a correlação extremos de temperatura e umidade mínima e os óbitos é maior, sendo que quando uma variável aumenta, ocorre o inverso com a outra, indicando que a correlação extremos das temperaturas e óbitos é uma associação negativa. Os extremos de temperatura máxima / óbitos, são variáveis que, ao terem os dados calculados por meio do coeficiente de Pearson, indicaram uma correlação mais próxima de 0 , o que indica que há uma baixa correlação entre as duas variáveis.

\section{CONSIDERAÇÕES FINAIS}

Sabendo que o presente trabalho tem como objetivo correlacionar os extremos termo-higrométricos e os registros de doenças respiratórias em Campo Grande-MS. E com essa correlação analisada através dos dados adquiridos, foi possível entender que os extremos de temperatura máxima, temperatura mínima e umidade mínima relativa do ar, tem relação com os casos de óbitos por meio de doenças no aparelho respiratório.

Ainda através desta pesquisa foi possível avaliar os períodos que requerem mais atenção para a saúde no que tange a problemas respiratórios, coincidindo com as mudanças no comportamento meteorológico, registrando eventos climáticos extremos no decorrer do ano, que podem ser considerados agravantes para a ocorrência de doenças respiratórias. Quando atingidos os eventos extremos de temperatura, mínima e máxima, e de umidade mínima relativa do ar, os casos de óbitos por doenças respiratórias tendem a serem maiores, sendo que tal informação pode ser utilizada pelo poder público para nortear as políticas públicas de saúde de modo a mitigar os efeitos de tais eventos de temperatura e umidade na vida da população.

As análises realizadas nesse trabalho, também podem servir de base para outras pesquisas que busquem aprofundar os efeitos dos eventos extremos termo-higrométricos sobre a qualidade de vida da população, objetivando, sobretudo, a promoção do bem-estar social e ambiental.

Além dos possíveis usos dos resultados deste trabalho para os órgãos ligados à saúde da população, a presente pesquisa poderá ser usada, também, na busca por melhoria da infraestrutura de forma a minimizar o desconforto gerado pelos extremos termo-higrométricos, sendo que para obter resultados significantes é essencial que tais melhorias prezem pelo conforto ambiental e de forma que seja acessível à população de maneira abrangente.

Concluindo, entendemos ser possível perceber a importância dos resultados obtidos neste trabalho, pois o mesmo pode servir de base para buscar a redução dos registros de óbitos da população por doenças no aparelho respiratório, desde que sejam tomadas atitudes de prevenção em períodos em que ocorrem os agravantes climáticos. Ter essa percepção é de suma relevância para entender o quanto os extremos de temperatura e umidade podem influenciar na saúde pública, culminando na melhoria da qualidade de vida da população em geral, colaborando para diminuir o número de doentes, bem como a superlotação dos postos de atendimento à saúde.

\section{AGRADECIMENTOS}

Ao IFMS pelo apoio financeiro.

\section{REFERÊNCIAS}

CAMPO GRANDE NEWS. Inmet alerta para umidade abaixo de $12 \%$ na Capital e onda de calor em MS. Disponível em: https://www.campograndenews.com.br/meio-ambiente/inmet-alerta-paraumidade-abaixo-de-12-na-capital-e-onda-de-calor-em-ms. Acesso em: 26 nov. 2019.

DATASUS. Departamento de Informática do SUS. Disponível em: http://datasus.saude.gov.br/. Acesso em: 12 set. 2019.

EL PAÍS. Esqueceram-se dos 70.000 mortos da onda de calor de 2003. Disponível em: https://brasil.elpais.com/brasil/2019/03/26/internacional/1553626291_625535.html. Acesso em: 26 nov. 2019.

INMET. Instituto Nacional de Meteorologia. Disponível em: www.inmet.gov.br. Acesso em: 10 set. 2019.

DOI: http://dx.doi.org/10.14393/Hygeia17058046 $\quad$ Hygeia $\quad$ v.17 $\quad$ p.146-160, 2021 página 159


MENDES, P. C. Gênese e estrutura espacial das chuvas na cidade de Uberlândia - MG. 2001. 258 f. Dissertação (Mestrado em Geografia) - Programa de Pós-Graduação em Geografia, Universidade Federal de Uberlândia, Uberlândia, 2001.

MENDONÇA, F.; DANNI-OLIVEIRA, I. M. Climatologia: noções básicas e climas do Brasil. São Paulo: Oficina de textos, 2007.

O estudo do clima urbano no Brasil: Evolução, tendências e alguns desafios. In: MENDONÇA, F.; MONTEIRO, C. A. F. (Org.). Clima urbano. São Paulo: Contexto, 2003. p.175-192.

MONTEIRO, A.; CARVALHO, V. Clima e planejamento regional. In: AMORIM, M. C. C. T.; SANT'ANNA NETO, J. L.; MONTEIRO, A. (Org.). Climatologia urbana e regional: questões teóricas e estudos de caso. São Paulo: Outras Expressões, 2013. P. 93-116.

Riscos climáticos: hazards, áleas, episódios extremos. In: AMORIM, M. C. C. T.; SANT'ANNA NETO, J. L.; MONTEIRO, A. (Org.). Climatologia urbana e regional: questões teóricas e estudos de caso. São Paulo: Outras Expressões, 2013. P. 143-172.

MONTEIRO, C. A. de F. Clima e excepcionalismo: conjecturas sobre o desempenho da atmosfera como fenômeno geográfico. Florianópolis: Ed. da UFSC, 1991. 233 p.

MURARA, P. G. Variabilidade Climática e Doenças Circulatórias e Respiratórias em Florianópolis(SC): uma contribuição à Climatologia Médica. Dissertação (Mestrado em Geografia). Florianópolis (SC). 2012. 94f. Universidade Federal de Santa Catarina. Disponível em: $<$ https://repositorio.ufsc.br/xmlui/bitstream/handle/123456789/99358/307856.pdf7sequenceM\&isAllow ed=y>. Acesso em: 07 abr. 2019.

NAGHETTINI, Mauro; PINTO, Éber José de Andrade. Hidrologia estatística. Belo Horizonte: CPRM, 2007. $552 \mathrm{p}$.

SETTE, Denise Maria; RIBEIRO, Helena. INTERAÇÕES ENTRE O CLIMA, O TEMPO E A SAÚDE HUMANA. Revista Interfacehs, São Paulo, v. 6, n. 2, p.37-51, ago. 2011. Disponível em: http://www3.sp.senac.br/hotsites/blogs/InterfacEHS/wp-

Content/uploads/2013/08/3_ARTIGO_vol6n2.pdf. Acesso em: 07 out. 2019.

SOUSA, T.C.M., AMANCIO, F., HACON, S.S., BARCELLOS, C. Doenças sensíveis ao clima no Brasil e no mundo: revisão sistemática. Rev Panam Salud Publica. 2018;42:e85.

https://doi.org/10.26633/RPSP.2018.85. 